\title{
BREVES REFLEXÕES SOBRE O PERSONALISMO EM EMMANUEL MOUNIER
}

\author{
BRIEF REFLECTIONS ON PERSONALISM IN EMMANUEL MOUNIER
}

\author{
Lélio Favacho Braga ${ }^{1}$ \\ ORCID:https://orcid.org/0000-0002-0855-9269 \\ Antônio Joaquim Severino ${ }^{2}$
}

\section{RESUMO}

Este ensaio, de cunho bibliográfico e teórico, traz uma breve reflexão sobre o personalismo em Emmanuel Mounier. O objetivo é de buscar o sentido que as pessoas atribuem ao pensamento desse autor, como um ser-com-o-outro, e a noção de comunidade como uma estrutura social mais adequada para o ser humano efetivar sua natureza relacional. Das posições personalistas, conclui-se que a liberdade e a responsabilidade são vistas como necessárias para o sujeito não ser objetifica do em seu existir real, considerando que a pessoa é alguém no mundo, e na relação com o outro, constrói sua história. É da ruptura dessa relação que decorrem os contrassensos da humanidade, a alienação e a miséria material do ser humano. Como o personalismo não é somente uma explicação teórica da condição existencial, mas também uma vontade sobre o homem, nasce daí a exigência do compromisso prático com vistas a desalienar o ser humano em Mounier.

Palavras-chave: Emmanuel Mounier. Personalismo. Pessoa. Construção Humana.

\section{INTRODUÇÃO}

O personalismo de Mounier ficou conhecido em meados do Século XX, em um contexto histórico desenhado pelas consequências da crise econômica de 1929 e do processo de ascensão do nazismo em 1933. O momento conturbado da década de 30 apontava a existência de uma crise densa na sociedade da época. Nesse contexto, o Personalismo mounierista é apresentado na Revista Esprit, fundada no ano de 1932, quando Mounier publicou seus primeiros escritos. A Revista Esprit era um excelente espaço para outros estudiosos manifestarem seus posicionamentos e reflexões. Foi criada para tratar das questões voltadas para a consciência e a dignidade humana frente aos impactos concretos da realidade histórica do momento. O Personalismo se apresenta

\footnotetext{
${ }^{1}$ Doutorando em Educação - Área de concentração em Teorias, Políticas e Culturas em Educação pela Universidade Nove de Julho - UNINOVE/SP, sob a orientação do Prof. Dr. Antônio Joaquim Severino. E-mail: leliofavacho@gmail.com

2 Doutorado em Filosofia pela Pontifícia Universidade Católica de São Paulo, PUC, Brasil. Professor titular, aposentado, de Filosofia da Educação da Universidade de São Paulo, USP, Brasil, ora atuando como docente colaborador. Professor contratado da Universidade Nove de Julho, UNINOVE/SP, Brasil, onde integra o corpo docente do Programa de Pós-Graduação em Educação e lidera o Grupo de Pesquisa e Estudo em Filosofia da Educação - GRUPEFE. E-mail: ajsev@uol.com.br
} 
como proposta de uma “filosofia de ação", comprometida não só

em interpretar essa realidade, mas, sobretudo, em transformá-la.

Mounier (1972) vê o outro como pessoa, e isso significa compreender o valor absoluto do que seja o ser humano, em função do qual devem ser pensados todos os fins da organização política. "O Personalismo expressa significativo potencial tanto como

filosofia quanto como pedagogia política, qualificando-se simultaneamente como instrumento de análise dessa realidade e como roteiro de ação transformadora" (SEVERINO, 2009, p.04). Devido à presença do ser humano no mundo, ele passa por transformações causadas por sua interação social, a qual consiste em transformar o outro e a si mesmo.

\section{O PERSONALISMO DE MOUNIER}

De acordo com Mounier (1972), em qualquer questão, é necessário distinguir os 'dados vis' dos 'dados nobres', em consonância com a procura de uma perspectiva maior. Deve-se procurar a liberdade, inclusive no que tange às próprias convicções, quando descobertas como equivocados no transcorrer de alguma análise. Em razão disso, é necessário libertar-se de doutrinas que direcionem o olhar do homem, ainda que isso exprima uma disposição distinta em relação à antiga compreensão para continuar a ser fiel ao próprio espírito. Outra perspectiva é de que uma revolução qualquer não efetiva automaticamente a resolução da crise pela qual passa a sociedade ocidental do Século XX. No pensamento emancipador do filósofo, isso só aconteceria se enveredasse por uma significativa e integral revisão dos valores e mudança nas estruturas sociais e nas camadas dirigentes.

Que o apelo utópico que se põe no horizonte para o pensamento emancipador é o de transformar criaturas naturais em pessoas e de transformar as sociedades reificadas em comunidades de cidadãos livres, capazes de tomar seu destino histórico nas próprias mãos. Cabe a todos aqueles que lidam com o conhecimento, não construir sistemas de significantes abstratos, mas de contribuir com um pensamento criativo e crítico, para a leitura da opacidade social e histórica, lançando esclarecimento para sua superação, tendo sempre em vista a emancipação da sociedade pela emancipação das pessoas no seu interior. A idéia que me parece muito forte no personalismo mounierista é a razão de ser do conhecimento, o que lhe dá sua legitimação, é seu intransigente compromisso com a construção da cidadania, entendida como aquela qualidade de vida que permita a todos existir concretamente, fruindo efetivamente de todas as condições objetivas e subjetivas que constituem a própria infraestrutura de nossa existência real (SEVERINO, 2009, p.04-05). 
No ensaio intitulado $O$ personalismo e a revolução do Século XX, Mounier (1972) assevera que o personalismo teria que se desenvolver, inicialmente, obedecendo àsseguintes “linhasdeação":(a) Autonomia em relação aos partidos políticos, todavia, sem tomar para si um caráter anárquico ou apolítico. Para isso, seria imprescindível analisar todos os aspectos envolvidos na prática social, de modo que a opção e a s ações pessoais se inserissem em um processo coletivo; (b) As atividades e os meios de concretização precisariam ter demarcados os limites de maneira rigorosa, pois só afirmar os princípios não significa consistir em vigor absurdo ou mágico.

\begin{abstract}
Afilosofiapersonalistatemumdiferencial no sentidodeque "apela" para o engajamento. Ela engaja um engajamento. Para ela, o filósofo tem que ser simultaneamente profeta e pedagogo, respondendo pela denúncia, pelo anúncio e pelo encaminhamento de propostas de ação histórica. Não endossa o silêncio dos intelectuais, seja ele o silêncio da omissão ou não. Cobra necessária militância intelectual, não só pela análise fria e neutra, mas também pela crítica e pela proposta. Dos intelectuais, se espera um necessário compromisso político e que tenha discernimento competente e combatente. Essa fecundidade do Personalismo deriva de sua abrangência unificadora, de sua capacidade de fundar-se numa concepção integral da condição humana, superando tanto os reducionismos como os dualismos ontológicos que sempre marcaram a filosofia (SEVERINO, 2009, p.04).
\end{abstract}

A Filosofia de Mounier entende o homem sempre preocupado com o sentido de seu próprio existir, e toda a sua história mostra o esforço para desvendá-lo. Pode-se dizer que, em muitos aspectos, o homem ainda é uma incógnita a ser descoberta. "[...] A natureza nada mais nos dá, nada mais entrega ao nosso conhecimento racional do que um feixe infinitamente complicado de determinações, às quais não chegamos [...], além dos sistemasque formulamosparaassegurarnossamarcha"(MOUNIER, 2004,p.31).

Isso quer dizer que a pessoa não é apenas corpo, ela é reflexão, escapa a qualquer determinismo e ultrapassa as fronteiras da natureza.

A transcendentalidade do homem sobre a natureza na qual está originalmente inserido vem de sua capacidade distintiva de só ele conhecê-la e transformá-la, de sua exclusiva capacidade de amor, de liberdade, capacidade de superar o rígido determinismo que regula a natureza (SEVERINO, 1974, p. 54).

Mounier também trata das inquietações humanas na obra, O Personalismo, em que ele esclarece que o homem não se define, porquanto só os objetos são definíveis, ou seja, o homem está muito distante de ser um objeto, tampouco, um ser que pode ser definido. Nesse sentido, o Personalismo mounierista é uma filosofia da pessoa livre, 
criadora, aberta a descobertas e a mudanças. “[...] Mil fotografias sobrepostas não nos dãoumhomemqueanda,quepensaequequer"( $\quad$ MOUNIER, 2004, p.15).

A tal experiência ninguém pode ser condicionado, nem constrangido. Aqueles mais integralmente a realizam vão atraindo outros à sua roda, despertam os que dormem, e assim, de apelo em apelo, a humanidade vai-se libertando do pesado sono em que vegetava e que ainda a amortece. Quem se recusa a escutar esse apelo e a comprometer-se na experiência de uma vida pessoal, perde o seu sentido como se perde a sensibilidade de um órgão que já não funciona (MOUNIER, 2004, 16).

Para Mounier (2004), há um dualismo na existência criadora que, em determinado momento, tende à despersonalização, em que o ser humano se esconde dos seus impulsos criativos e dos seus desejos; e em outro, ao movimento de personalização, buscando se realizar como pessoa em um crescimento de construção humana transformadora. "[...] O homem é corpo exatamente como é espírito, é integralmente ‘corpo' e é integralmente 'espírito'. Dos seus mais primários instintos, comer, reproduzir-se, é capaz de passar a artes sutis: a culinária, a arte de amar" (MOUNIER, 2004, p. 29). Corpo e espírito estão, no pensamento de Mounier, formando uma das estruturas da pessoa, suas existências integradas.

Uma experiência, rica, que o mundo se insere, exprime-se por incessante criação de situações, de regras, de instituições. Mas sendo os recursos da pessoa indefinidos, nada do que a exprime a esgota, nada do que a condiciona a escraviza. Não sendo um objeto visível, também não é resíduo interno, qualquer substância escondida por detrás dos nossos comportamentos, princípio abstrato de nossos concretos gestos, se o fosse, seria ainda, por qualquer forma, um objeto ou um fantasma de objeto. É uma atividade vivida de autocriação, de comunicação e de adesão, que em ato, como movimento de personalização, alcançamos e conhecemos (MOUNIER, 2004, 16).

Monier (2004) enuncia que a interioridade e a exterioridade existem para manter o equilíbrio no plano do ter e do ser, pois, do contrário, os laços das relações interpessoais seriam desfeitos, o que levaria a pessoa ao estado de angústia. “ [...] As relações entre a pessoa e a natureza não são, pois, relações de pura exteriorização, mas relações dialéticas de permuta e ascensão" (MOUNIER, 2004, p.38). Com iss o, reconhece-se a indivisibilidade humana, ou seja, o ser humano é completo, capaz de transcender a natureza, de ir além, o que causa o movimento de personalização contra as amarras que limitam o refletir emancipado. Sobre isso, Mounier (2004, 32-41) assevera: 
O homem é um ser natural, mas é ser natural humano. E, exatamente, o homem singulariza-se por uma dupla capacidade de romper com a natureza. Só ele conhece esse universo que o absorve e só ele pode transformar, ele, o menos armado e o menos poderoso dos grandes animais. E, o que é infinitamente mais, é capaz de amar [...]. A perfeição do universo pessoal encarnado não é, pois, a perfeição de uma ordem como pretendem todas as filosofias (e todas as políticas) que pensam que o homem poderá um dia submeter totalmente o mundo. É perfeição de uma liberdade que combate, e que combate duramente. Por isso, subsiste até mesmo nas suas derrotas [...], o caminho próprio do homem está nesse otimismo trágico onde encontra a sua justa medida num clima de grandeza e de luta.

De acordo com o pensador, o ser humano está mergulhado na natureza e é parte dela, todavia está acima dela em umaparente paradoxo. “ Os determinismos existem, mas não são absolutos. Não chegam a romper o curso do destino do homem. Cada um deleslhetrazumanovapromessadeliberdade"(MOUNIER apud MOIX, 1968, p.135). $\mathrm{Na}$ verdade, a pessoa é dona de uma dimensão que não está reduzida à matéria. É só observar os espantos causados pela liberdade criadora do ser humano aos condicionamentosdeterminantes." [...] A liberdade é um movimento de um dinamismo simultâneo e essencialmente forte e frágil. Por sua impetuosidade original e quase que prometéica, consegue despertar e arrancar os espíritos levados e entorpecidos pelas situaçõesqueosalienam"(SEVERINO,1983,p.71).

Nessa liberdade, por exemplo, estão os elementos de uma educação que transforma o ser humano pelo fato de não alienar, pois, o tempo todo, está sendo construída, fazendo frente aos determinismos, dando o aporte para o pensamento livre em relação às amarras ideológicas nocivas ao bem comum. Nesse proceder, o apoderamento de sua consciência acontece no grau de compreensão como sujeito histórico, capaz de transformar sua realidadenaconcretudedavida. “ $\quad$ [...] Consciência e liberdade, as duas grandes marcas da transcendentalidade humana. É graças a elas que toma forma a personalidade humana, e elas transfigurarão toda a existência pessoal" (SEVERINO, 1983, p. 72). Convém observar que o termo 'apoderar-se' e suas derivações (como: apoderamento) são empregados, neste estudo, no sentido de a criatura humana prover-se de saberes para apreender (entendimento e compreensão) os elementos que abarcam a realidade concreta.

Em seu comentáriosobreopensamentodeMounier,Severinoobservaque“ $\quad[\ldots]$ a existência pessoal continuará sendo uma contínua e plena manifestação da bidimensionalidade do homem. Um ser imanente à natureza, mas simultaneamente, transcendendo-a" (SEVERINO, 1983, p. 72). Nesse sentido, as relações interpessoais 
ocorrem por meio da comunicação, que é um processo facilitador das relações. Isso implica o ato de se comunicar, inicialmente, de forma intrapessoal, buscando o diálogo consigo mesmo, momento necessário para mergulhar em si, na tentativa de se conhecer. Num segundo momento, a comunicação é feita de forma interpessoal, em que o diálogo com o outro promove uma experiência de universalidade, ou seja, expande a comunicação.

\begin{abstract}
Quando a comunicação se enfraquece ou se corrompe perco-me profundamente eu próprio: todas as loucuras são uma falha nas relações com os outros [...], torno-me também estranho a mim mesmo, alienado. Quase se poderia dizer que só existo na medida em que existo para os outros, ou numa frase-limite: ser é amar (MOUNIER, 2004, p.46).
\end{abstract}

Segundo Mounier, a comunicação é uma das dimensões mais importantes para o ser humano, porque é por meio dela que o homem estabelece relações consigo, com os outros homens e com o ambiente, experiencia a realidade com o outro e se percebe como um ser que existe a partir do outro. A comunicação consiste na face da doação, através da qual "[...] a generosidade dissolve a opacidade e anula a solidão da pessoa, mesmo quando ela nadarecebeemtroca"(MOUNIER,2004,p.47).

\title{
3 CONSTRUÇÃO HUMANA EM MOUNIER
}

Refletir sobre a pessoa, no âmbito do pensamento de Mounier, implica considerar a incompletude do ser humano e que suas dimensões não se desprendem do ser inacabado que o homem é. Para destacar mais particularmente essas dimensões, é preciso fazer um desmembramento metodológico delas, ainda que sucintamente, como, por exemplo, a dimensão pessoal da comunicação, fundamental no pensamento do referido autor, para se entender o modo como sua antropologia personalista compreende a construção da humanidade no humano.

Vários pensadores assinalam para a debilidade da tese de que o ser humano é construtor de sentidos na concretude da vida. Essa é uma das características mais marcantes da contemporaneidade, porquanto consiste em reinventar a dimensão da intersubjetividade. Entre elas, várias aconteceram no domínio da teoria do conhecimento, especificamente sobre questões referentes à linguagem. Mounier desata a referida perspectiva e reverte-a para o campo ético-político, assinalando as limitações e os riscos da propositura individualista.

Sobre o individualismo, Mounier o define como 
um sistema de costumes, de sentimentos, de idéias e de instituições que organiza o indivíduo partindo de atitudes de isolamento e defesa. Foi uma ideologia e a estrutura dominante da sociedade burguesa ocidental entre o século XVIII e o século XIX. Homem abstrato, sem vínculos nem comunidades naturais, deus supremo no centro duma liberdade sem direção nem medida, sempre pronto a olhar os outros com desconfiança, cálculo ou reivindicações (MOUNIER, 2004, p. 44-45).

O individualismo é uma proposta que se contrapõe a um sistema organicista que não reconhece a existência individual da pessoa e enfatiza o todo sem levar em consideração a parte. “ [...] É para a massa que resvala uma democracia liberal e parlamentar esquecida de que a democracia era primitivamente uma reivindicação da pessoa"(MOUNIER,1967,p.108).

Despersonalizadas em cada um de seus membros, e, além disso, despersonalizada como todo, a massa caracteriza-se por um misto singular de anarquia e de tirania, pela tirania do anônimo, de todas a mais vexatória, porquanto mascara todas as forças, essas sim, autenticamente denomináveis que se cobrem da sua impessoalidade. É para a massa que tende o mundo dos proletários, perdidos na servidão sombria das grandes cidades, dos edifícios-casernas, dos conformismos políticos, da máquina econômica (MOUNIER, 1967, p. 108).

Para Mounier (2004), o homem existe como construtor de sua história, razão porque também pode construir sua liberdade. Essa construção deve ser feita em coletividade, já que o homem é aquele que consegue interrogar e responder e responsável por unir o sujeito na coletividade. Ele tem a potencialidade de criar possibilidades de fazer escolhas em seu cotidiano. Portanto, para Mounier (2004, 108), "[...] o homem de ação realizado é aquele que vive no seu íntimo, esta dupla polaridade percorre agitando-se o caminho que vai de um a outro, combate a um tempo para asseguraraautonomiaeregularaforçadecadaumaoutro".

Ao conceber a pessoa como essa permanência aberta, Mounier decodifica bem a condição do homem, sujeito responsável pela construção da história, como garantindo uma medida comum e universal que une todos os homens, ao mesmo tempo em que reconhece sua encarnação empírica. As estruturas mediante as quais o Personalismo descreve o universo pessoal abrangem simultaneamente o absoluto de sua transcendentalidade, tanto quando o relativo da imanência instaurada por sua encarnação no mundo material. Todo o pensamento de Mounier articula-se em torno dessa intuição básica, de natureza antropológica, qual seja, a da apreensão da pessoa humana, que se realiza como uma unidade dialética de imanência e de transcendência (SEVERINO, 2009, p.04). 
Infere-se que o Personalismo mounierista é uma Filosofia de ação, por não conceber uma distância entre teoria e prática. Contrariamente, nosso autor defende que a teoria e a prática devem caminhar juntas. Assim pensando, ele dirige um novo olhar ao estudo do homem, ao conceber as questões humanistas no processo de personalização da pessoa e do coletivo. Mounier (2004) não direciona sua filosofia para os mais altos graus do intelecto, já que envereda seu pensamento na concretude da vida, para a vida real e emancipada.

Refletir sobre a pessoa, em Mounier, é falar da construção humana, que está em um processo de ida e vinda, de encontrar em si as possibilidades que a vida oferece, o que implica estar aberto para isso. Isso significa procurar maneiras de se encontrar, de não se fechar em si mesmo, buscando perspectivas de mudanças para se personalizar. Mounier (2004, p.17) entende que "[...] só muito lentamente é que a consciência se vai libertandodomineral,daplantaoudoanimalqueemnóspesam”(MOUNIER,1967,p.

21). Oserhumanonãose desenvolve“ [...] somente no plano da consciência, mas em toda a sua grandeza, no plano do esforço humano, para humanizar a humanidade." (MOUNIER, 1967, p. 21).

Sob o ponto de vista de Mounier, a vida é modelada por meio das ações e das inquietudes da realidade concreta, que, no limite, é capaz de determinar as ações humanas. Nesse processo, abre-se a possibilidade de o ser humano passar a ser o arquiteto de sua história, ao determinar suas ações de forma consciente e livre de amarras ideológicas massacrantes no entrelaçar da vida, como a invasão das propagandas midiáticas de cunho econômico ou político, entre outros, que levam sorrateiramente a mente humana à acomodação e ao consumo naturalizados por ideologias nocivas ao desenvolvimento de atitudes emancipadas. Para Mounier, a pessoa se institui por meio da e para a comunidade, porquanto é fruto dela. Comentando o pensamento de Mounier, Moix refere:

\footnotetext{
A comunidade não nasce de pessoas que se apagam, mas que se promovem plenamente... O nós comunitário só se realiza a partir do dia em que " cada um dos membros descobriu cada um dos outros como uma Pessoa, e começa a tratá-la como tal, a compreendê-la como tal". Impossível fundar uma comunidade esquivando -se da pessoa (MOIX, 1968, p.152).
}

Segundo Mounier (2004), é na relação com os semelhantes que o ser humano se concretiza como pessoa, ou seja, a pessoa é construída na comunidade. No mundo comunitário, a ação é traçada na convivência com outras consciências na concretude da 
vida. Mounier (2004) concebe que a primeira ação da pessoa deve ser de criar com os semelhantes em comunidade, onde as culturas, as estruturas, os sentimentos “[...] e até instituições estejam marcados pela sua natureza de pessoas; sociedade de que apenas começamos a entrever e a esboçar os costumes. Funda-se numa série de atos originais que não têm equivalente em mais parte nenhuma no universo" (MOUNIER, 2004, p.4647).

\begin{abstract}
$1^{\circ}$ - Sair de nós próprios. A pessoa é uma existência capaz de se libertar de si própria, de se desapossar, de se descentrar para se tornar disponível aos outros. [...] Só liberta o mundo e os homens aquele que primeiramente se libertou a si próprio [...]. $2^{\circ}$ - Compreender. Deixar de me colocar sempre no meu próprio ponto de vista, para me situar no ponto de vista dos outros. Não me procurar numa pessoa escolhida e igual a mim, não conhecer os outros apenas com um conhecimento geral [...], mas captar com a minha singularidade a sua singularidade, numa atitude de acolhimento e num esforço de recolhimento. Ser todo para todos sem deixar de ser eu e de ser eu [...]. $3^{\circ}$ - Tomar sobre nós, assumir o destino, os desgostos, as alegrias, as tarefas dos outros, "sofrer na nossa própria carne". $4^{\circ}$ - Dar. A força viva do ímpeto pessoal não está nem na reivindicação $[\ldots]$ nem na luta de morte $[\ldots]$, mas na generosidade [...] e na dádiva sem medida e sem esperança de recompensa. A economia da pessoa é uma economia de dádiva, não de compensação ou de cálculo. $5^{\circ}$ - Ser fiel. A aventura da pessoa é uma aventura constante desde o nascimento à morte. As dedicações pessoais, amor, amizade, só podem ser perfeitas na continuidade. Essa continuidade não é uma exibição, uma repetição uniforme [...], mas um contínuo renovamento. A fidelidade pessoal é uma fidelidade criadora (MOUNIER, 2004, p.47-48).
\end{abstract}

\title{
4 REFLEXÕES FINAIS
}

De acordo com o que foi abordado sobre o Personalismo em Mounier (2004), intui-se que o autor entende que as ações originais possibilitam o ressurgimento da comunicação no convívio das pessoas. Mas aparecem entraves que afastam a possibilidade de que haja essa comunicação. "[...] É a avidez de presença: mas o mundo inteiro de pessoas está maciçamente ausente" (MOUNIER, 2004, p.50). Os entraves abrem possibilidades para o isolamento, que, em muitos casos, resulta em um ser humano que, ainda que esteja em meio a relações, elas não o fazem ser e, muito menos, crescer. “[...] A comunicação é mais rara do que a felicidade, mais frágil do que a beleza. Um nada a pode suspender ou quebrar entre duas pessoas; como podemos, pois, esperá-la entre um grande número"? (MOUNIER, 2004, p.50).

De acordo com os aspectos destacados sobre esse rico pensamento, entende-se que a comunicação interpessoal é uma experiência fundamental do homem como 
espécie. Sob esse ponto de vista, as pessoas e a comunidade não se separam. As pessoas se compreendem por meio da comunidade, que está acima da sociedade. Pensar com Mounier (2004) trouxe a percepção de que os contrassensos na humanidade são resultados da alienação do ser humano. De acordo com esse pensador (2004), a miséria material decorre da alienação humana, o que se configura como desalienação do indivíduo. Com base nesse pressuposto, o personalismo mounierista se aproxima das posições de fundo do marxismo e se contrapõe ao capitalismo, quando separa a pessoa da máquina. Nesse sentido, a existência humana vale mais do que a ideia capitalista de imprescindibilidade do labor, a despeito do trabalho consistir em satisfação e efetivação da labuta.

Considerando essas premissas sinteticamente apresentadas, é possível vislumbrar a relevância que o personalismo atribui à educação para construir as pessoas e a civilização humana. Isso se justifica porque só será possível fundar a comunidade com pessoas solidamente constituídas, porquanto o amadurecimento da comunidade é vinculado ao desabrochar das pessoas. A educação é fundamentalmente o aprendizado da comunidade, em que a aprendizagem do eu se faz, simultaneamente, com a aprendizagem do tu.

Pode-se afirmar que a comunidade pessoal perfeita é, historicamente, uma imagem limite, um horizonte que se deve manter em vista. É inalcançável devido à própria contingência do existir, preço da encarnação. As nossas serão sempre comunidades imperfeitas. Mas, eis aí uma utopia fecunda para o combate ao individualismo egoísta e ao coletivismo impessoal. E a educação, basicamente, é mediação concreta para instaurar a solidariedade, malha que se tece quando o outro é reconhecido como parceiro do eu (Cf. SEVERINO, 2001).

$\mathrm{Na}$ condição de prática especificamente voltada para os sujeitos humanos em construção, para os quais se desenvolve uma ação de intervenção, seu compromisso fundamental é com o respeito radical à sua dignidade. Com efeito, a legitimidade da educação pressupõe, necessariamente, sua eticidade. Esse compromisso ético da educação, que se estende ao exercício profissional dos educadores, por assim dizer, acirra-se nas coordenadas histórico-sociais em que nos encontramos, porque as forças de dominação, de degradação, de opressão e de alienação se consolidaram nas estruturas sociais, econômicas e culturais. As condições de trabalho ainda são muito degradantes, as relações de poder, muito opressivas, e a vivência cultural, precária e alienante. A distribuição dos bens naturais, dos bens políticos e dos bens simbólicos é muito 
desigual. Em outras palavras, as condições atuais de existência da humanidade, traduzidas pela efetivação de suas mediações objetivas, são extremamente injustas e desumanizadoras.

\begin{abstract}
This essay, of a bibliographical and theoretical nature, develops a brief reflection on personalism in Emmanuel Mounier. The aim is to seek the meaning that people have attributed to the thought of this author, as a being-with-the-other, and the notion of community as a social structure more adequate for the human being to effect his/her relational nature. From personalistic positions, it is concluded that freedom and responsibility are seen as necessary for the subject not to be objectified in his/her real existence, considering that the person consists of one in the world, and in the relationship with the other, builds his/her history. It is from the rupture of this relationship that the contradictions of humanity, the alienation and the material misery of the human being take place. As personalism is not only a theoretical explanation of the existential condition, but also a will over man, there arises the demand of the practical commitment with a view to the disalienation of the human being in Mounier.
\end{abstract}

Keywords: Emmanuel Mounier. Personalism. Person. Human construction.

\title{
REFERÊNCIAS
}

MOIX, Candide. O pensamento de Emmanuel Mounier. Tradução de Frei Marcelo L. Simões. Rio de Janeiro: Paz e Terra, p. 135, 152, 1968.

MOUNIER, Emmanuel. O Personalismo. Trad. Vinícius Eduardo Alves. São Paulo: Centauro, p. 15,16, 17, 29, 31, 32, 38, 41, 44, 45, 46, 47, 2004.

. A esperança dos desesperados: Malraux, Camus, Sartre, Bernanos. trad. Naumi Vasconcelos. Rio de Janeiro: Paz e Terra, 1972.

Manifesto ao serviço do personalismo. Tradução de Antônio Ramos. Lisboa: Morais, p.21, 108, 1967.

SEVERINO, Antônio Joaquim. Humanismo, personalismo e os desafios sociais da educação contemporânea. v. 18, n. 36, jan./abr. Cuiabá. Revista Educação Pública,p.04-05, 2009.

Pessoa e existência: iniciação ao personalismo de Emmanuel Mounier. São Paulo: Cortez Editora, p.71, 72, 1983.

Saraiva, p.54, 1974.

A antropologia personalista de Emmanuel Mounier. São Paulo:

Educação, sujeito e história. SãoPaulo:Olhod’Água,2001.

$/ 01 / 2017$

$/ 03 / 2017$

Revista Temas em Educação, João Pessoa, v.26, n. 1, p. 86-96, jan.-jun. 2017. 